\title{
How Soil Moisture Affects Photosynthetic Characteristics of Aralia elata Leaves
}

\author{
Jie Zhao, Rui Yang, Xiaohua Liu, Guangcan Zhang, Shuyong Zhang* \\ Shandong Province Key Laboratory of Soil Erosion and Ecological Restoration, \\ Key Laboratory of Agricultural Ecology and Environment, Forestry College, Shandong Agricultural University, \\ Taian, 271018, China
}

Received: 20 July 2017

Accepted: 18 September 2017

\begin{abstract}
Using a CIRAS-2 portable photosynthesis system, the photosynthesis, transpiration, and light responses of Aralia elata were studied under different soil moisture values with the aim of understanding the adaptability of this species to different light and soil water conditions. The results showed that the net photosynthetic rate $\left(P_{\mathrm{n}}\right)$, transpiration rate $\left(T_{\mathrm{r}}\right)$, and water use efficiency (WUE) of $A$. elata varied in response to different levels of photon flux density $(P F D)$. When $P F D$ was between 800 and 1,800 $\mu \mathrm{mol} \mathrm{m} \mathrm{m}^{-2} \mathrm{~s}^{-1}, P_{\mathrm{n}}$ changed little in response to the increasing light intensity, whereas $T_{\mathrm{r}}$ decreased gradually and WUE increased significantly. Light saturation point $(L S P)$ and light compensation point $(L C P)$ were approximately 800 and $30 \mu \mathrm{mol} \mathrm{m}^{-2} \mathrm{~s}^{-1}$, respectively. The soil water content had little effect on $L S P$ and $L C P$, but significantly affected photosynthetic quantum efficiency $(\Phi)$ and dark respiratory rate $\left(R_{\mathrm{d}}\right)$. By defining the $P_{\mathrm{n}}$ and $W U E$ as the indexes of plant productivity and soil water efficiency, respectively, the soil moisture availability and productivity of $A$. elata were graded and evaluated, and six types of soil water grading were established. Thus, at $R W C$ values between $44.5 \%$ and $79.2 \%$ in which both $P_{\mathrm{n}}$ and $W U E$ were maintained at a high level, the results can provide theoretical support for highly productive and efficienct water management in A. elata.
\end{abstract}

Keywords: net photosynthetic rate, WUE, availability of soil moisture, evaluation of photosynthetic productivity, Aralia elata

\section{Introduction}

Light and water are important ecological factors in plant physiology and growth [1-4]. In recent years, with the changes in the global climate and the aggravation of environmental problems such as soil erosion and desertification, environmental stress factors have

*e-mail: zhsy@sdau.edu.cn clearly limited plant growth and development [5-7]. In a natural environment, soil moisture in different regions is obviously influenced by rainfall, runoff, leakage, and evaporation, which in turn affect a series of physiological changes in plants such as water status, photosynthesis, and material transport [8-11]. Therefore, we explored the photosynthetic, transpiration, and light responses of plants under different soil water conditions [12-14]. These results contributed to our understanding of the adaptive characteristics of plant physiological processes to light and water, and provide physiological and ecological 
evidence for the scientific introduction, cultivation, and management of this species.

Photosynthesis is not only related to structure and physiological function of the genetic characteristics of the species themselves [15], but it is also affected by ecological factors such as light, temperature, and soil moisture [16-18]. Under drought stress, plants can regulate and adjust the physiological pathways of leaf movement through stomatal regulation so as to achieve a balance between carbon assimilation and water loss [19]. To improve the $W U E$ is the main adaptation strategy for plant survival and reproduction in arid areas. According to the limiting factors of ecology, it can be seen that there are different levels of threshold values of the plant physiological processes with reference to soil moisture, and what extremely high or low water levels can affect [20-21]. In recent years the changes of plant anatomical structure, physiological and biochemical factors under different water conditions, and its adaptation characteristics and mechanism to water stress were investigated and discussed [22-23]. However, the study of physiological processes under different soil water conditions was limited to PEG habitat and single potting simulation under 3-4 water stresses. Also, the studies on the quantitative relationships between photosynthesis, transpiration, moisture, and light are limited.

A. elata, which belongs to the Araliaceae family, is a perennial deciduous small arbor species with a high medicinal and edible value [24] that is also used in landscaping to conserve water and soil [25]. With decreases in wild resources and increases in market demand of this species, people are paying more attention to resource protection, introduction, and cultivation. Thus far, most of the studies performed on A. elata have been confined to its pharmacological action, edible value, artificial breeding, and cultivation techniques [26-27]. The physiological and ecological processes, photosynthetic productivity, and suitable water conditions for the growth of $A$. elata under different soil water conditions were still not clear. Therefore, in this paper, the light responses of photosynthetic physiological parameters of 2-year-old $A$. elata were studied and the quantitative relationships between photosynthetic physiological parameters and soil water content as well as light intensity were analyzed to investigate the physiological adaptability of $A$. elata to environmental changes. Meanwhile, $P_{n}$ and $W U E$ as the indexes of plant productivity and soil water efficiency at light saturation point, respectively, were defined. Based on photosynthetic and physiological parameters, soil moisture availability and productivity of $A$. elata were graded and evaluated. Moreover, the high productivity and high efficiency water range of plants were determined, which could provide the theoretical basis and technical guidance for the introduction, cultivation, and management of $A$. elata.

\section{Experimental Procedures}

\section{Experimental Site Description}

The experimental site is located at the forestry experimental station, Shandong Agricultural University, Taian City, at north latitude $35^{\circ} 38^{\prime} \sim 36^{\circ} 33^{\prime}$ and east longitude $116^{\circ} 02^{\prime} \sim 117^{\circ} 59^{\prime}$. This area has a semi-humid, warm temperate, continental monsoon climate with four hot rainy seasons. The average annual precipitation is $741.8 \mathrm{~mm}$, most of which falls in July, August, and September. The annual average temperature is $12.9^{\circ} \mathrm{C}$, with the highest temperature on record in July $\left(26.4^{\circ} \mathrm{C}\right.$ on average) and the lowest temperature on record in January $\left(-2.6^{\circ} \mathrm{C}\right.$ on average $)$. The extreme highest temperature on record was $41^{\circ} \mathrm{C}$ and the lowest temperature was $-27.5^{\circ} \mathrm{C}$. The annual accumulated temperature over $10^{\circ} \mathrm{C}$ is $2,350^{\circ} \mathrm{C} \sim 4,777^{\circ} \mathrm{C}$, and the average frost-free period is 195 days. The main soil types are cinnamon soil and brown soil.

\section{Experimental Material and Humidity Control}

Nine two-year-old $A$. elata seedlings were used as the experimental samples. These plants exhibited strong growth vigor and were not infected with disease or insect pests. In late March 2016, nine pots $(0.6 \mathrm{~m}$ in diameter and $1.2 \mathrm{~m}$ deep, with drainage holes at the bottom; the shape of the pot is cylindrical, and the volume per pot is $0.34 \mathrm{~m}^{3}$ ) containing brown soil were prepared to conduct the pot experiment, the average height of the plants was $58.6 \pm 1.3 \mathrm{~cm}$ and the average diameter at chest height was $1.62 \pm 0.32 \mathrm{~cm}$, and the management was underway by July. When the experiment was finished, the soil around the plant root was dug up by ring sampling, and each pot was measured three times. The average field capacity and soil density of the pots were $26.1 \pm 1.3 \%$ and $1.34 \pm 0.12 \mathrm{~g} \mathrm{~cm}^{-3}$, respectively.

Different degrees of soil water stress were imposed by changing the water content in the field environment (the pots were buried in the soil for a long time to ensure that the pot and field soil were at the same temperature). First, two days before the experimental observations we provided sufficient water until moisture saturation was reached and we determined gravimetric water content ( $M W C$; \%) using an oven-drying method with an $L N W$ $50 A$ neutron probe $(C A S$, Nanjing, Jiangsu, CHN). For comparability with other tree species over the literature, relative soil water content $(R W C)$ was calculated as the ratio of $M W C$ and field capacity $(F C ; \%)$ by ring sampling [28]. Two days later we obtained the initial water content ( $M W C$ of $26.0 \%, R W C$ of $99.6 \%$ ) and for the first time the physiological parameters of photosynthesis and transpiration were measured. Then, based on natural water consumption, we obtained the soil water content every two days. When the $M W C$ values were $22.7 \%$, 
$19.6 \%, 17.2 \%, 14.6 \%, 12.8 \%, 9.8 \%$, and $7.3 \%(R W C$ values were $87.0 \%, 75.1 \%, 65.9 \%, 55.9 \%, 49.0 \%, 37.5 \%$, and $28.0 \%$, respectively), we measured photosynthesis, transpiration, and light.

\section{Photosynthetic Response to Light}

Three strong seedlings of pot-cultured $A$. elata were selected from the nine seedlings, and three strong mature leaves were selected from the top of each seedling. We repeatedly measured each sample leaf three times and calculated the mean value for further analysis. Photosynthesis, transpiration, and light responses of $A$. elata under different soil conditions were measured using a portable photosynthesis system (CIRAS-2, PP System, UK). To reduce the effect of light fluctuations, all measurements were collected between 09:00 and 11:00 in all of the soil moisture treatments. During this time environmental factors, for example external light intensity, air temperature, atmospheric moisture and atmospheric $\mathrm{CO}_{2}$ concentration, were similar.

During each measurement, $\mathrm{CO}_{2}$ concentration, air temperature, and relative humidity were maintained at $375 \pm 6.0 \mathrm{ppm}, 25-26^{\circ} \mathrm{C}$, and $65 \pm 3.0 \%$, respectively, by using a CIRAS-2 portable photosynthesis system. For each observation, $P F D$ was controlled at 1,800, 1,600, $1,400,1,200,1,000,800,600,400,250,150,100,50$, and $20 \mu \mathrm{mol} \mathrm{m} \mathrm{m}^{-2} \mathrm{~s}^{-1}$, respectively. The measuring time was $120 \mathrm{~s}$ under each $P F D$. The photosynthesis system automatically recorded the physiological indexes, such as the net photosynthetic rate $\left(P_{\mathrm{n}}\right), P F D$, transpiration rate $\left(T_{\mathrm{r}}\right)$, stomatal conductance $\left(G_{\mathrm{s}}\right)$, and intercellular $\mathrm{CO}_{2}$ concentration $\left(C_{\mathrm{i}}\right)$, etc. Leaf $W U E$ was calculated as follows [29]:

$$
W U E=P_{n} / T_{r}
$$

\section{Data Processing and Regression Analysis}

The experimental data were analyzed using SPSS 12.0 software and statistical techniques such as variance analysis and logistic analysis were carried out. A nonrectangular hyperbolic model was used to fit the photosynthetic light response curves of $A$. elata under the different water contents and to calculate the specific parameters.

The model expression is [30-31].

$$
\begin{gathered}
P_{n}=\left[\left(\frac{\left(\Phi P F D+P_{n \max }-\sqrt{\left(\Phi \cdot P F D+P_{n \max }\right)^{2}-}\right.}{4 \cdot \Phi \cdot P F D \cdot k \cdot P_{n \max }}\right) / 2 k-R_{d}\right]
\end{gathered}
$$

...where $P_{\mathrm{n}}$ is net photosynthetic rate, $P F D$ is photon flux density, $P_{\text {nmax }}{ }^{n}$ is maximum net photosynthetic rate, $\Phi$ is photosynthetic quantum efficiency, $R_{\mathrm{d}}$ is dark respiration rate, and $k$ is inflection point of the photosynthetic lightresponse curve.

The light compensation point $(L C P)$ of photosynthesis was calculated using the following formula [32]:

$$
L C P=\frac{R_{d} \cdot P_{n \max }-k \cdot R_{d}^{2}}{\Phi\left(P_{n \max }-R_{d}\right)}
$$

The light saturation point ( $L S P$ ) of photosynthesis can be directly obtained from the light response curve [33].
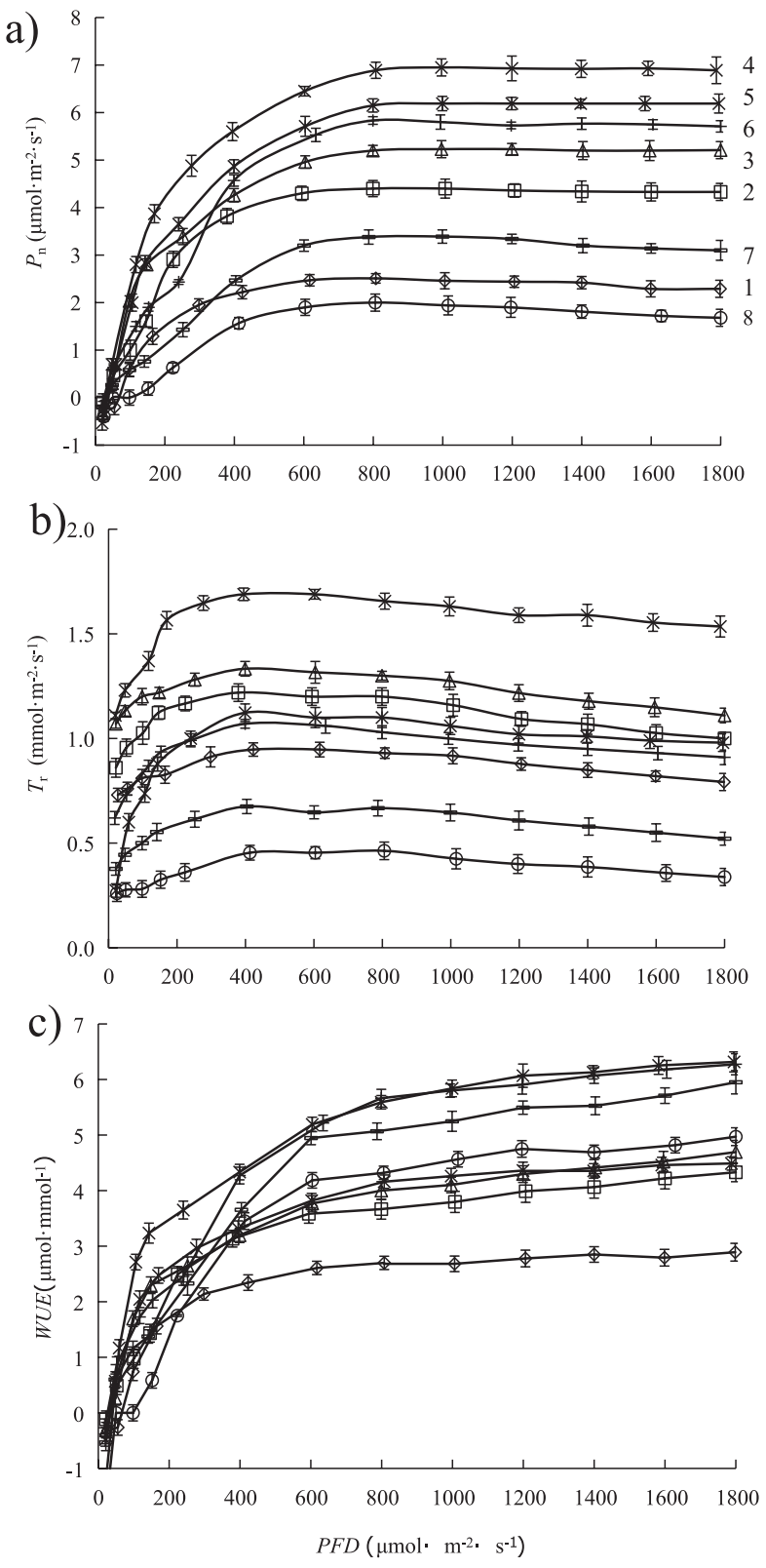

Fig. 1. Light response processes of net photosynthetic rate $\left(P_{\mathrm{n}}\right)$, transpiration rate $\left(T_{\mathrm{r}}\right)$, and water use efficiency $(W U E)$ of $A$. elata under different relative soil water contents with: 1) $99.6 \%, 2$ ) $87.0 \%$, 3) $75.1 \%$, 4) $65.9 \%$, 5) $55.9 \%$, 6) $49.0 \%$, 7) $37.5 \%$, and 8) $28.0 \%$. Points are the mean of at least 27 replicate $P_{n}, T_{r}$, and WUE responses for each light. Vertical bars indicate \pm 1 SE of the means. Lines are fitted to the response of $P_{\mathrm{n}}, T_{\mathrm{r}}$, and $W U E$ to light. 


\section{Results}

Photosynthetic Response of $A$. elata

\section{Leaves to Light}

The photosynthetic light response of $A$. elata was similar under different soil water contents (Fig. 1). Below a $P F D$ of $800 \mu \mathrm{mol} \mathrm{m} \mathrm{m}^{-2} \mathrm{~s}^{-1}$, the $P_{\mathrm{n}}$ exhibited a significant increasing trend with an increase in $P F D$. However, when the $P F D$ was higher than this value, $P_{\mathrm{n}}$ stabilized at a certain level. This showed that the light intensity threshold of $A$. elata photosynthesis was the $L S P$, and the corresponding $P_{\mathrm{n}}$ value was the maximum net photosynthetic rate $\left(P_{\text {nmax }}^{\mathrm{n}}\right)$ of $A$. elata. This also showed that the adaptability of $A$. elata photosynthesis to light intensity was strong, and under the same water content photosynthesis was maintained at a high level within a $P F D$ range of 800 to $1,800 \mu \mathrm{mol} \mathrm{m} \mathrm{m}^{-2} \mathrm{~s}^{-1}$. The $L S P$ was little affected by the changes in soil moisture, and stabilized at a $P F D$ value of approximately $800 \mu \mathrm{mol} \mathrm{m} \mathrm{m}^{-2} \mathrm{~s}^{-1}$ (or approximately $600 \mu \mathrm{mol} \mathrm{m} \mathrm{m}^{-2} \mathrm{~s}^{-1}$ when the $R W C$ was $99.6 \%$ or $28.0 \%$ ).

The variance analysis showed that $P_{\text {nmax }}$ and $\Phi$ of $A$. elata differed significantly under different soil
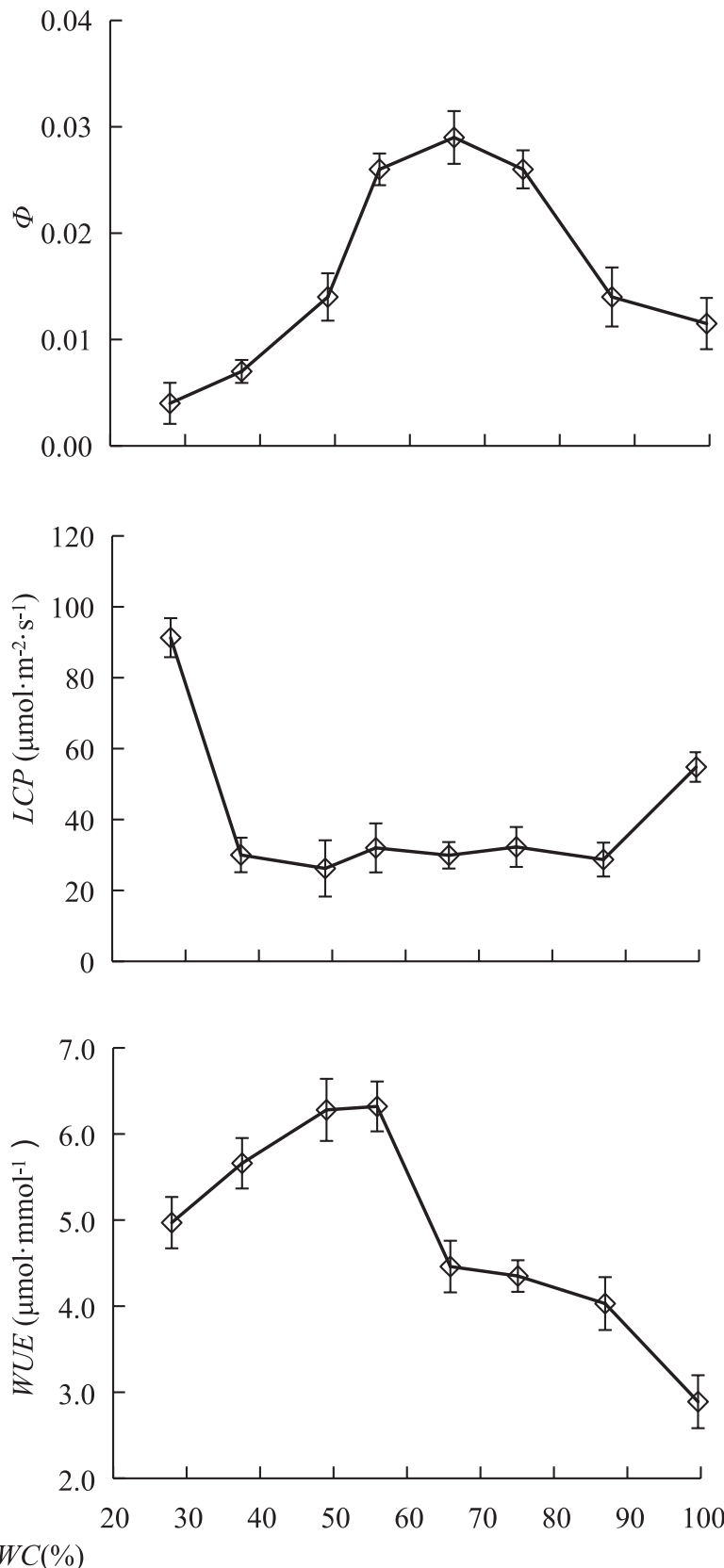

Fig. 2. The net photosynthesis rate $\left(P_{\mathrm{n}}\right)$, apparent photosynthetic quantum yield $(\Phi)$, dark respiratory rate $\left(R_{\mathrm{d}}\right)$, light compensation point $(L C P)$, transpiration rate $\left(T_{\mathrm{r}}\right)$, and water use efficiency $(W U E)$ of $A$. elata under different soil moisture conditions. Each point represents the mean of at least three plants with 27 replicate $P_{\mathrm{n}}, \Phi, R_{\mathrm{d}}, L C P, T_{\mathrm{r}}$ and $W U E$ for each $R W C$. Regression lines were fit using a polynomial expression. Error bars represent $\pm 1 \mathrm{SE}$ of the mean. 
moisture contents $(P<0.01)$; the maximum photosyn-

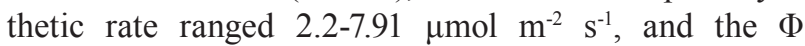
ranged $0.004-0.029 \mu \mathrm{mol} \mathrm{m} \mathrm{m}^{-2} \mathrm{~s}^{-1}$. The $P_{\text {nmax }}$ and $\Phi$ of A. elata decreased significantly with a change (increase or decrease) in soil water content (Fig. 2). As the soil water content increased, $P_{\text {nmax }}$ and $\Phi$ increased rapidly. When $R W C$ reached a certain threshold ( $R W C$ was approximately $65.9 \%), P_{\text {max }}$ and $\Phi$ reached their highest levels of $7.92 \mu \mathrm{mol} \mathrm{m} \mathrm{m}^{-2} \mathrm{~s}^{-1}$ and $0.029 \mu \mathrm{mol} \mathrm{m} \mathrm{m}^{-2} \mathrm{~s}^{-1}$, respectively. After reaching the maximum, these variables gradually decreased with an increase in the $R W C$.

The dark respiration rate $\left(R_{\mathrm{d}}\right)$ of $A$. elata ranged $0.24-0.86 \mu \mathrm{mol} \mathrm{m}{ }^{-2} \mathrm{~s}^{-1}$ and exhibited clear threshold value responses to $R W C$ (Fig. 2). When $R W C$ was between $55.9 \%$ and $75.1 \%, R_{\mathrm{d}}$ was maintained at a high level of approximately $0.85 \mu \mathrm{mol} \mathrm{m} \mathrm{m}^{-2} \mathrm{~s}^{-1}$. However, when $R W C<75.1 \%$ or $>55.9 \%, R_{\mathrm{d}}$ decreased significantly to respective values of approximately $0.43 \mu \mathrm{mol} \mathrm{m} \mathrm{m}^{-2} \mathrm{~s}^{-1}$ and $0.26 \mu \mathrm{mol} \mathrm{m} \mathrm{m}^{-2} \mathrm{~s}^{-1}$. The $L C P$ of $A$. elata ranged from 26.2-91.2 $\mu \mathrm{mol} \mathrm{m} \mathrm{m}^{-2} \mathrm{~s}^{-1}$ and was less influenced by the changes in soil moisture. When $R W C$ was between $37.5 \%$ and $87.0 \%, L C P$ was maintained at approximately $30 \mu \mathrm{mol} \mathrm{m} \mathrm{m}^{-2} \mathrm{~s}^{-1}$. However, when $R W C$ was $99.6 \%$ or $28.0 \%, L C P$ increased significantly to respective values of $54.8 \mu \mathrm{mol} \mathrm{m} \mathrm{m}^{-2} \mathrm{~s}^{-1}$ and $91.2 \mu \mathrm{mol} \mathrm{m} \mathrm{m}^{-2} \mathrm{~s}^{-1}$.

\section{Transpirational Response of $A$. elata to Light}

Under different soil water contents, response of transpiration in A. elata similar to changes in $P F D$ (Figs 1 and 2). When $P F D$ was less than $400 \mu \mathrm{mol} \mathrm{m} \mathrm{m}^{-2} \mathrm{~s}^{-1}$, $\mathrm{T}_{\mathrm{r}}$ increased rapidly with an increase in $P F D$; when $R W C$ was higher than this value, $T_{\mathrm{r}}$ showed a gradual decreasing trend. The maximum transpiration rate $\left(T_{\text {rmax }}\right)$ of $A$. elata was measured at a $P F D$ of $400 \mu \mathrm{mol} \mathrm{m} \mathrm{m}^{-2} \mathrm{~s}^{-1}$; above this value, $T_{\mathrm{r}}$ exhibited a decreasing trend. $T_{\mathrm{r} \max }$ maximum rate of transpiration measured under the various soil moisture contents was in the range $0.45-1.69 \mu \mathrm{mol} \mathrm{m} \mathrm{m}^{-2} \mathrm{~s}^{-1}$. The variance analysis showed that $T_{\text {rmax }}$ differed significantly under the various soil water contents $(P<0.01)$. When $R W C=65.9 \%, T_{\mathrm{r}}$ reached a maximum value of $1.69 \mathrm{mmol} \mathrm{m}^{-2} \mathrm{~s}^{-1}$, and an increase or decrease in the soil water content led to a decrease in $T_{\mathrm{r}}$.

\section{Leaf WUE of $A$. elata in Response to Light}

Under different soil moisture contents, the leaf $W U E$ of $A$. elata showed a gradual increasing trend with an increase in $P F D$, and no asymptote was reached (Fig. 1). At a $P F D<400 \mu \mathrm{mol} \mathrm{m} \mathrm{m}^{-2} \mathrm{~s}^{-1}$, the $W U E$ increased considerably with an increase in $P F D$. However, when the $P F D$ exceeded this value, the $W U E$ increased slowly with an increase in $P F D$. This showed that $A$. elata leaf $W U E$ can be improved under strong light. However, this response varied significantly under different soil moisture conditions. Under the highest light intensity $\left(P F D=1,800 \mu \mathrm{mol} \mathrm{m} \mathrm{m}^{-2} \mathrm{~s}^{-1}\right)$, the maximum water use efficiency $\left(W U E_{\max }\right)$ was in the range of $2.9 \sim 6.3 \mu \mathrm{mol}$ $\mathrm{mol}^{-1}$. WUE $E_{\max }$ gradually increased with an increase in the soil water content and reached a maximum value $\left(W U E_{\max }=6.3 \mu \mathrm{mol} \mathrm{mol}{ }^{-1}\right)$ when $R W C=55.9 \%$. At $R W C$ values higher than this value, $W U E_{\max }$ decreased obviously. This showed that higher soil moisture will lead to lower $W U E$ in $A$. elata.

\section{Net Photosynthetic Rate and Water Use Efficiency of A. elata in Responses to Soil Moisture}

We analyzed the photosynthetic response of $A$. elata to soil moisture using the $R W C$ value that corresponded to $P_{\mathrm{n}}$ at $P F D=1,000 \mu \mathrm{mol} \mathrm{m} \mathrm{m}^{-2} \mathrm{~s}^{-1}$ (i.e., light-saturating conditions; Fig. 3). (This $P F D$ value exceeded the $L S P$, and under various soil moisture conditions, $P_{\mathrm{n}}$ of $A$. elata remained basically unchanged with increasing light intensity.) The fitting results were in agreement with the quadratic equation. Thus, the value of $R W C$ that corresponded to $P_{\text {nmax }}$ was $65.9 \%$; the values of $R W C$ that corresponded to $P_{\mathrm{n}}=0$ were $21.0 \%$ and $108 \%$. When the $R W C$ exceeds $100 \%$, it has no actual biological significance and $108 \%$ should be replaced by the measured maximum of $99.6 \%$.The integration according to the fitting equation was:
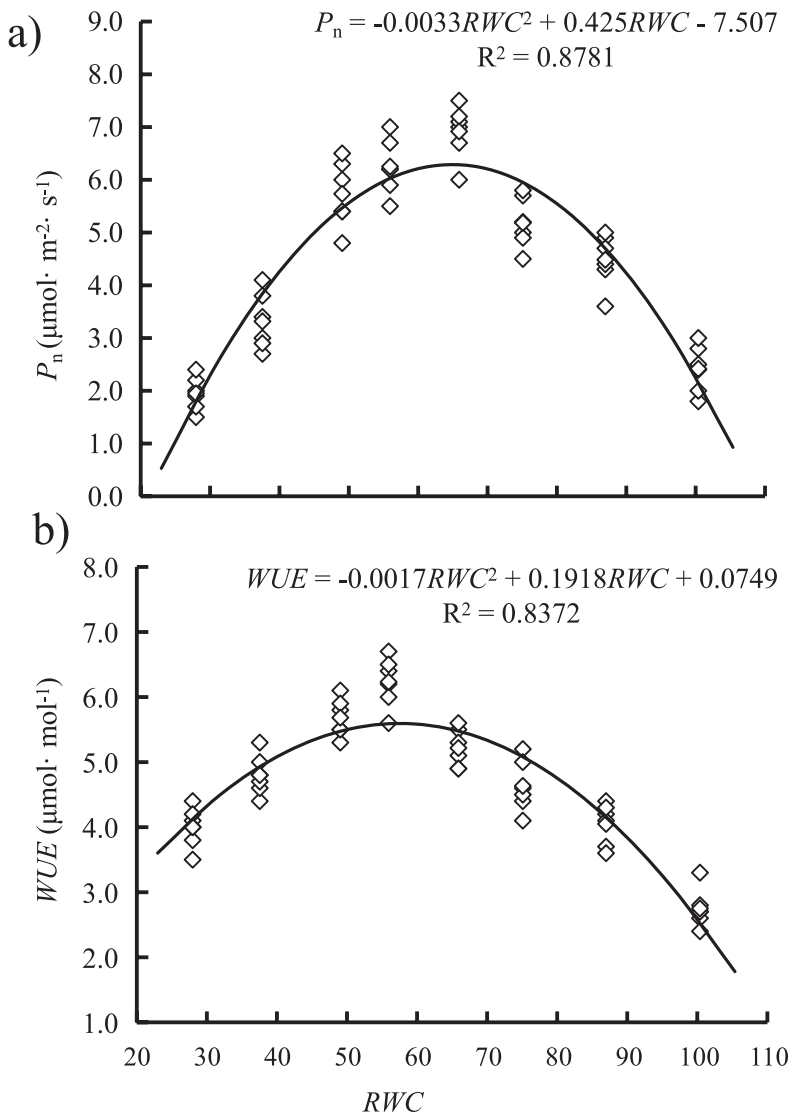

Fig. 3. The responses of net photosynthetic rate $\left(P_{\mathrm{n}}\right)$ and water use efficiency (WUE) of $A$. elata to soil moisture under $P F D=1,000 \mu \mathrm{mol} \mathrm{m} \mathrm{m}^{-2} \mathrm{~s}^{-1}$. Regression lines were fit using a polynomial expression. Lines are fitted to the response of $P_{\mathrm{n}}$ and WUE to $R W C$. 


$$
\overline{P_{n}}=\frac{1}{99.6-28.0} \int_{28.0}^{99.6}\left[-0.0033 x^{2}+0.425 x-7.507\right] d x
$$

When $R W C$ was in the range of approximately 28.0 99.6\%, the values of $P_{\mathrm{n}}$ were calculated using the integral fitting equation. The mean $P_{\mathrm{n}}$ value was $4.7 \mu \mathrm{mol}$ $\mathrm{m}^{-2} \mathrm{~s}^{-1}$, and the corresponding $R W C$ values were $44.5 \%$ and $85.1 \%$. Therefore, A. elata photosynthesis stabilized at a high $R W C$ that ranged from $44.5 \%$ to $85.1 \%$. The most suitable $R W C$ was $64.5 \%$, and the minimum $R W C$ that sustained photosynthesis was $21.3 \%$.

The response of $W U E$ to soil moisture were also in agreement with the quadratic equation under the saturated light intensity of photosynthesis $(P F D=1,000$ $\left.\mu \mathrm{mol} \cdot \mathrm{m}^{-2} \cdot \mathrm{s}^{-1}\right)$. Thus, the value of $R W C$ that corresponded to $W U E_{\max }$ was $55.9 \%$. The integration according to the fitting equation was:

$$
\overline{W U E}=\frac{1}{99.6-28.0} \int_{28.0}^{99.6}\left[-0.017 x^{2}+0.1918 x+0.0749\right] d x
$$

When $R W C$ was in the range of approximately $28.0 \sim 99.6 \%$, the values of $W U E$ were obtained from the integral fitting equation. The mean $W U E$ value was $4.6 \mathrm{~mol} \cdot \mathrm{mol}^{-1}$, and the corresponding $R W C$ values were $34.6 \%$ and $79.2 \%$, respectively. Therefore, A. elata photosynthesis was stabilized at a high $R W C$ in the range $34.6-79.2 \%$.

\section{Grading and Evaluating Soil Water Availability and Productivity}

Grading criteria of soil moisture were based on plant water physiology theory and the results of moisture threshold analysis combined with the response rule of photosynthetic process to soil moisture. Based on the physiological significance of determining the critical water points, the classification and evaluation criteria of soil water availability of $A$. elata were studied (Table 1). The water point at $P_{\mathrm{n}}=0$ was taken as a critical water point, and a water point lower than this value was considered as non-productive and non-efficient. The water point corresponding to $P_{\text {nmax }}$ and $W U E_{\max }$ was taken as the high productivity and high efficiency water point, respectively. The mean values of $P_{\mathrm{n}}$ and $W U E$ that corresponded to $R W C$ values were calculated using the integral fitting equation. Water points above average were considered as the medium productivity and medium efficiency water points, and water points below average were considered as the low productivity and low efficiency water points. In this study, six types of the soil water gradings of $A$. elata were established based on the size of $P_{\mathrm{n}}$ and $W U E$ under different soil water contents. The $R W C$ of less than $21.3 \%$ corresponded to non-productivity and non-efficiency water; the $R W C$ of $21.3-34.6 \%$ and $85.1-99.6 \%$ corresponded to low productivity and low efficiency water; the $R W C$ of $34.6-44.5 \%$ and $79.2-85.1 \%$ corresponded to low productivity and medium efficiency water, and medium productivity and low efficiency water, respectively; the $R W C$ of $44.5-55.9 \%$ and $64.5-79.2 \%$ corresponded to medium productivity and medium efficiency water. The $R W C$ of $55.9-64.5 \%$ corresponded to high productivity and high efficiency water. In this range (55.9-64.5\%), A. elata had the highest photosynthetic capacity and efficient physiological characteristics for water consumption. As a result, the soil water should be maintained in the range of 44.5-79.2\%, in which $P_{\mathrm{n}}$ and $W U E$ can reach their maximum values of $60 \%$ and $70 \%$, respectively, so that the $A$. elata can attain higher productivity and efficiency.

\section{Discussion}

The factors that affect $\Phi$ of plant photosynthesis are internal physiological factors such as the carbon metabolism pathway, respiration, pigment content, etc., and environmental factors such as light, temperature, water, etc. [34-37]. Studies have shown that an unsuitable soil moisture level (too high or too low) can lead to a decrease in plant $\Phi$ [38-40], but the quantitative

Table 1. critical water point of photosynthetic efficiency and its threshold grade in leaves of $A$. elata.

\begin{tabular}{|c|c|c|c|}
\hline Critical index of soil water & Critical point of $R W C$ & Grading of soil water availability & Threshold grade of $R W C$ \\
\hline WCP $P_{n}$ & $21.3 \%, 99.6 \%$ & NPNEW & $<21.3 \%$ \\
\hline WSP ${ }_{\mathrm{n}}$ & $64.50 \%$ & LPLEW & $21.3-34.6 \% ; 85.1-99.6 \%$ \\
\hline $\mathrm{WSP} W U E$ & $55.90 \%$ & LPMEW & $34.6-44.5 \%$ \\
\hline $\mathrm{MVP} P_{\mathrm{n}}$ & $44.5 \%, 85.1 \%$ & MPLEW & $79.2-85.1 \%$ \\
\hline $\mathrm{MVP} W U E$ & $34.6 \%, 79.2 \%$ & MPMEW & $44.5-55.9 \% ; 64.5-79.2 \%$ \\
\hline & & HPHEW & $55.9-64.5 \%$ \\
\hline
\end{tabular}

1) $\mathrm{WCP} P_{\mathrm{n}}$, water compensation point of net photosynthetic rate; WS $P_{\mathrm{n}}$, water saturation point of net photosynthetic rate; WSP $W U E$, water saturation point of water use efficiency; $W V P P_{n}$, mean value point of net photosynthetic rate; WVPWUE, mean value point of water use efficiency. 2) NPNEW, no-productivity and no-efficiency water; LPLEW, low-productivity and low-efficiency water; LPMEW, low-productivity and medium-efficiency water; MPLEW, medium-productivity and low-efficiency water; MPMEW, medium-productivity and medium-efficiency water; HPHEW, high-productivity and high-efficiency water 
relationship between soil moisture and $\Phi$ has not been reported for different plants. This study shows that the $\Phi$ of $A$. elata that corresponded to changes in soil moisture ranged between 0.004 and 0.029 ; an approximate " $\cap$ "shaped quantitative relationship existed between these variables (Fig. 2). When $R W C$ was in the range 55.9-75.1\%, the $\Phi$ of $A$. elata was higher than 0.26 (approximately $90 \%$ of its maximum level); however, when $R W C$ was outside of this range, $\Phi$ decreased obviously. When $R W C$ ranged $49.0-87.0 \%$, $\Phi$ was 0.014 (approximately $48 \%$ of its maximum level). This indicates that soil moisture has a significant effect on the $\Phi$ of $A$. elata.

$\Phi$ is an index that reflects a plant's capacity to absorb, transform, and utilize light under low-light conditions [41]. Measurements of plant $\Phi$ generally range from 0.03 to 0.05 under suitable conditions. The maximum value of $\Phi$ of $A$. elata was approximately 0.029 , i.e., less than $\Phi$ of plants in general. The results show that the $\Phi$ of $A$. elata is low under low-light conditions, i.e., light use efficiency is low.

The $L S P$ and the $L C P$ are two main indexes that reflect the light requirement characteristics of plants [42-45]. The study shows that the A. elata LSP and LCP were little affected by variation in the soil moisture content. When the water content was within the range $37.5-87.0 \%, L S P$ and $L C P$ were $800 \mu \mathrm{mol} \mathrm{m} \mathrm{m}^{-2} \mathrm{~s}^{-1}$ (Fig. 1) and $30 \mu \mathrm{mol} \mathrm{m} \mathrm{m}^{-2} \mathrm{~s}^{-1}$ (Fig. 2), respectively. Plants can be divided into heliophilous species and sciophytes according to their light intensity requirements. LSP of heliophilous species is generally above $540 \mu \mathrm{mol} \mathrm{m} \mathrm{m}^{-2} \mathrm{~s}^{-1}$ and $L C P$ is in the range of $13 \sim 36 \mu \mathrm{mol} \mathrm{m} \mathrm{m}^{-2} \mathrm{~s}^{-1}$, while $L S P$ of sciophytes is generally $90 \sim 180 \mu \mathrm{mol} \mathrm{m} \mathrm{m}^{-2} \mathrm{~s}^{-1}$, and $L C P$ is below $10 \mu \mathrm{mol} \mathrm{m}^{-2} \mathrm{~s}^{-1}$ [46]. The $A$. elata $L S P$ and $L C P$ were similar to typical heliophilous plants. When $P F D$ was in the range $800 \sim 1,800 \mu \mathrm{mol} \mathrm{m} \mathrm{m}^{-2} \mathrm{~s}^{-1}$ and light intensity was increased, A. elata photosynthetic rate did not decrease significantly, but $T_{\mathrm{r}}$ decreased continuously and leaf $W U E$ obviously increased (Fig. 1). This indicates that $A$. elata photosynthesis responds strongly to light, and the ability of this plant to use low levels of light is poor. Therefore, A. elata has a strong adaptability to high light conditions, it can improve $W U E$ to adapt to strong light stress.

Research has shown that plants have a certain degree of adaptability and resistance to soil water deficits, and various physiological activities are increased in the moderate water deficit range [47-50]. This range varies in different plant species and for different physiological processes. $P_{\mathrm{n}}$ of $A$. elata stabilized at a high soil water content that ranged $44.5-85.1 \%$; an $R W C$ of $64.5 \%$ was the optimum soil moisture content for photosynthesis (Fig. 3). Within this $R W C$ range, A. elata transpiration was maintained at a high level (Fig. 2), and an $R W C$ of $65.9 \%$ was the optimum soil moisture content for transpiration. As the leaf $W U E$ is affected by photosynthetic and transpiration rates, the suitable soil water content of $W U E$ was different from that of photosynthesis. A. elata $W U E$ stabilized at a high soil water content that ranged $34.6-79.2 \%$; an $R W C$ of $55.9 \%$ resulted in the highest $W U E$ (Fig. 3). At present, one of the most important problems in the water management of $A$. elata is to achieve highly efficient utilization of water resources and to improve photosynthetic productivity. Therefore, we quantified the "productivity" (biomass) and "efficiency" (root resistance to water absorption) in traditional agricultural research, and graded the soil water of A. elata into non-productivity and non-efficiency water (NPNEW), low-productivity and low-efficiency water (LPLEW), low-productivity and medium-efficiency water (LPMEW), medium-productivity and low-efficiency water (MPLEW), medium-productivity and mediumefficiency water (MPMEW), and high-productivity and high-efficiency water (HPHEW). As a result, the soil water should be maintained in the range of $44.5 \%$ to $79.2 \%$, in which $P_{\mathrm{n}}$ and $W U E$ can reach their maximum values of $60 \%$ and $70 \%$, respectively, so that the A. elata can obtain higher productivity and efficiency. The results can provide theoretical support for water management of $A$. elata. Relevant results show a suitable $R W C$ of $40.6 \sim 60.4 \%$ for Juglans regia [51], 47.5 64.2\% for Robinia pseudoacacia [52], 40.5 52.0\% for Platycladus orientalis [52], and 58.8 76.6\% for Syringa oblate [53]. Compared with the moderate soil water deficit range of these plants, A. elata can maintain a high photosynthetic rate and high $W U E$ under a relatively higher soil water deficit.

\section{Conclusions}

The results show that photosynthesis, transpiration, and water use efficiency of $A$. elata were closely correlative to soil moisture and light intensity and had a notable threshold of responses. Light responses of physiological parameters exhibited higher plasticity, indicating that $A$. elata had better adaptability to light and soil water conditions.

At $44.5 \% \leq R W C \leq 79.2 \%$ was the economic water threshold value that maintained higher productivity and efficiency. Therefore, it can provide theoretical support for highly productive and highly efficient water management in A. elata.

\section{Acknowledgements}

This work was financially supported by research and demonstration of the key technology of vegetation restoration and reconstruction in the open pit of the eastern Shandong hilly area (201504406), and the National Natural Science Foundation of China (No. 31370702).

\section{References}

1. XIA J.B., ZHANG G.C., SUN J.K., LIU X. Threshold effects of photosynthetic and physiological parameters in Prunus sibirica to soil moisture and light intensity. Acta. Pharmacol. Sin. 35 (3), 322, 2011. 
2. RAKIĆ T., GAJIĆ G., LAZAREVIĆ M., STEVANOVIĆ B. Effects of different light intensities, $\mathrm{CO}_{2}$ concentrations, temperatures and drought stress on photosynthetic activity in two paleoendemic resurrection plant species Ramonda serbica and R. nathaliae. Environ. Exp. Bot. 109 (109), 63, 2015.

3. HAZRATI S., TAHMASEBI-SARVESRANI Z., MODARRES-SANAVY S.A., MOKHTASSI-BIDGOLI A., NICOLA S. Effects of water stress and light intensity on chlorophyll fluorescence parameters and pigments of Aloe vera L. Plant. Physiol. Bioch. 106, 141, 2016.

4. CELIA S.E., BENJAMÍN V.P., JOSÉ A.C. Assessing differences in water- and light-use efficiency in two related fir species under contrasting light conditions: gas exchange instantaneous rates $v s$. integrated C fixation and water loss. Environ. Exp. Bot. 122, 49, 2016.

5. XIA J.B., ZHANG S.Y., ZHANG G.C., XIE W.J., LU Z.H. Critical responses of photosynthetic efficiency in Campsis radicans (L.) Seem to soil water and light intensities. Afr. J. Biotechnol. 10 (77), 17748, 2011.

6. HU J.C., CAO W.X., ZHANG J.B., JIANG D., FENG J. Quantifying responses of winter wheat physiological processes to soil water stress for use in growth simulation modeling. Pedosphere. 14 (4), 509, 2004.

7. LAMCHIN M., LEE J.Y., LEE W.K., LEE E.J., KIM M., LIM C.H., CHOI H.A., KIM S.R. Assessment of land cover change and desertification using remote sensing technology in a local region of Mongolia. Adv. Space. Res. 57 (1), 64, 2016.

8. LIU X.P., FAN Y.Y., LONG J.X., WEI R.F., KGELGREN R., GONG C.M., ZHAO J. Effects of soil water and nitrogen availability on photosynthesis and water use efficiency of Robinia pseudoacacia seedlings. J. Environ. Sci-China. 25 (3), 585, 2013.

9. SOFO A., DICHIO B., MONTANARO G., XILOYANNIS C. Photosynthetic performance and light response of two olive cultivars under different water and light regimes. Photosynthetic. 47 (4), 602, 2009.

10. RIVAS R., Falcão H.M., RIBEIRO R.V., MACHADO E.C., Pimentel C., Santos M.G. Drought tolerance in cowpea species is driven by less sensitivity of leaf gas exchange to water deficit and rapid recovery of photosynthesis after rehydration. S. Afr. J. Bot. 103, 101, 2016.

11. FUENTEALBA M.P., ZHANG J., KENWORTHY K., ERICKSON J., KRUSE J., TRENHOLM L. Transpiration responses of warm-season turfgrass in relation to progressive soil drying. Sci. Hortic-Amsterdam. 198, 249, 2016.

12. ZHANG Z.Z., ZHAO P., NI G.Y., ZHU L.W., ZHAO X.H. Water use of re-vegetation pioneer tree species Schima superba and Acacia mangium in hilly land of South China. Chinese Journal of Applied Ecology. 25 (4), 931, 2014

13. ZHANG W.Q., ZENG L.H., WANG M.H., YIN Z.Y., ZHOU P., CHEN S.G. The photosynthetic physiological characteristics of main tree species in the upper and middle reaches of Dongjiang watershed. Ecology and Environmental Sciences. 20 (1), 51, 2011.

14. ZHANG S.Y., ZHANG G.C., LIU X., XIA J.B. The responses of photosynthetic rate and stomatal conductance of Fraxinus rhynchophylla to differences in $\mathrm{CO}_{2}$ concentration and soil moisture. Photosynthetica. 51 (3), 359, 2013.

15. SAJAD M.Z., NANCY G., MUSLIMA N., REETIKA M., FIRDOSE A.M., NAGEEBUL R.S., ASIF B.S., SALGOTRA R.K. Impact of drought on photosynthesis: Molecular perspective. Plant. Gene. 2017.

16. BEATRYCZE N., KRUK J. Powered by light: Phototrophy and photosynthesis in prokaryotes and its evolution. Micro- biol. Res. 186, 99, 2016.

17. OSWALDO F., AURÉLIE M., JACQUES W. Differential effect of regulated deficit irrigation on growth and photosynthesis in young peach trees intercropped with grass. Eur. J. Agron. 81, 106, 2016.

18. GREER D.H. Responses of biomass accumulation, photosynthesis and the net carbon budget to high canopy temperatures of Vitis vinifera, L. cv. Semillon vines grown in field conditions. Environ. Exp. Bot. 138, 10, 2017.

19. RIZWAN Z., HAORAN D., MUHAMMAD A., WENQING Z., YOUHUA W., ZHIGUO Z. Potassium fertilizer improves drought stress alleviation potential in cotton by enhancing photosynthesis and carbohydrate metabolism. Environ. Exp. Bot. 137, 73, 2017.

20. LIU E.K., MEI X.R., YAN C.R., GONG D.Z., ZHANG Y.Q. Effects of water stress on photosynthetic characteristics, dry matter translocation and WUE in two winter wheat genotypes. Agr. Water. Manage. 167, 75, 2016.

21. LI J.H., CANG Z.M., JIAO F., BAI X.J., DING Z., ZHAI R.C. Influence of drought stress on photosynthetic characteristics and protective enzymes of potato at seedling stage. Journal of the Saudi Society of Agricultural Sciences. 16 (1), 82, 2015

22. DANIELE C., LIOR R., ELISABETTA B., MARCO C. Xylem anatomical traits reveal different strategies of two Mediterranean oaks to cope with drought and warming. Environ. Exp. Bot. 133, 128, 2017.

23. CAO Y.N., MA C.X., CHEN G.C., ZHANG J.F., XING B.S. Physiological and biochemical responses of Salix integra Thunb. under copper stress as affected by soil flooding. Environ. Pollut. 225, 644, 2017.

24. HUANG F.S., ZHAO H.T., ZHOU K.Q., LI F.H., ZHANG K.W. Study on Distribution Characteristics of the Total Aralosides Content in Aralia elata (Miq.) Seem. Chinese. Wild. Plant. Resources. 33, 1, 2014.

25. ZHANG M.P., GAO Y.G. Study on cutting root reproduction of Aralia elata. Chinese Agricultural Science Bulletin. 21, 237, 2005

26. ZHANG X.P., YIN L.Y., NIU W.Y., LIU J.W., XIAO H.B. Antitumor effect of congmuye total saponins on tumor cells in vitro. Lishizhen Medicine and Materia Medica Research. 23 (12), 2966, 2012.

27. ZHANG P., SHEN H.L. Cultivation techniques of Aralia elata planted for edible and medicinal purposes. Nonwood Forest Research. 29, 69, 2011.

28. LANG Y., WANG M., XIA J.B., ZHAO Q.K. Effects of soil drought stress on photosynthetic gas exchange traits and chlorophyll fluorescence in Forsythia suspensa. Journal of Forestry Research. 4, 1, 2017.

29. FARQUHAR G.D., SHARKEY T.D. Stomatal conductance and photosynthesis. Annual Review of Plant Physiology. 33 (33), 317, 1982

30. LANG Y., ZHANG G.C., ZHANG Z.K., LIU S.S., LIU D.H., HU X.L. Light response of photosynthesisand its simulation in leaves of Prunus sibirica L.under different soil water conditions. Acta. Ecologica. Sinica. 31, 4499, 2011.

31. ZHOU H.H., CHEN Y.N., LI W.H., CHEN Y.P., FU L.X. Photosynthesis of Populus euphratica and its response to elevated $\mathrm{CO}_{2}$ concentration in an arid environment. Progress in Natural Science. 19 (4), 443, 2008

32. LANG Y., ZHANG G.C., ZHANG Z.K., LIU S.S,. LIU D.H,. HU X.L. Light response of photosynthesisand its simulation in leaves of Prunus sibirica L.under different soil water conditions[J]. Acta Ecologica Sinica, 31 (16), 4499, 2011. 
33. LANG Y., WANG M., ZHANG G.C., ZHAO Q.K. Experimental and simulated light responses of photosynthesis in leaves of three tree species under different soil water conditions. Photosynthetica. 51 (3), 370, 2013.

34. KAKANI V.G., VU J.C., ALLEN L.H.Jr., BOOTE K.J. Leaf photosynthesis and carbohydrates of $\mathrm{CO}_{2}$-enriched maize and grain sorghum exposed to a short period of soil water deficit during vegetative development. J. Plant. Physiol. 168 (16), 2169, 2011.

35. VERCAMPT H., KOLEVA L., VASSILEV A., HOREMANS N., BIERMANS G., VANGRONSVELD J., CUYPERS A. The functional role of the photosynthetic apparatus in the recovery of Brassica napus plants from preemergent metazachlor exposure. J. Plant. Physiol .196-197, 99, 2016.

36. LIU C.G., WANG Y.J., PAN K.W., JIN Y.Q., LI W., ZHANG L. Effects of phosphorus application on photosynthetic carbon and nitrogen metabolism, water use efficiency and growth of dwarf bamboo (Fargesia rufa) subjected to water deficit. Plant. Physiol. Bioch. 96 (9), 20, 2015.

37. SEKHAR K.M., SREEHARSHA R.V., REDDY A.R. Differential responses in photosynthesis, growth and biomass yields in two mulberry genotypes grown under elevated $\mathrm{CO}_{2}$ atmosphere. J. Photoch. Photobio. B. 151, 172, 2015.

38. DAVIES F.S., FLOER J.A. Short-term flooding effects on gas exchange and quantum yield of rabbiteye blueberry (Vaccinium ashei Reade). Plant. Physiol. 81 (1), 289, 1986.

39. ZHU Y.Y., HE K.N., TANG D.F., GONG Y.X. Response to light of Ulmus pumila in different soil moisture. Research of Soil and Water Conservation. 14, 92, 2007.

40. ZHANG S.Y., ZHOU Z.F., XIA J.B., ZHANG G.S. The responses of Euonymus fortunei var. radicans sieb. leaf photosynthesis to light in different soil moisture. Acta. Botanica. Boreali-Occidentalia. Sinica. 27 (12), 2514, 2007.

41. LI H.S. MODERN plant physiology. Beijing Higher Education Press. Beijing. 2002.

42. LIU G., ZHANG G.C., LIU X. Responses of Cotinus coggygria var. cinerea photosynthesis to soil drought stress. Chinese Journal of Applied Ecology. 21 (7), 1697, 2010.

43. LANG Y., WANG M. Effects of soil water on photosynthesis of Forsythia suspensa (Thunb.) Vahl in spring and summer. Acta. Ecologica. Sinica. 35 (9), 3043, 2015.
44. COLLIER C.J., ADAMS M.P., LANGLOIS L., WAYCOTT M., O'BRIEN K.R., MAXWELL P.S., MCKENZIE L. Thresholds for morphological response to light reduction for four tropical seagrass species. Ecol. Indic. 67, 358, 2016.

45. AASAMAA K., APHALO P.J. Effect of vegetational shade and its components on stomatal responses to red, blue and green light in two deciduous tree species with different shade tolerance. Environ. Exp. Bot. 121, 94, 2016.

46. MENG F.J. Plant Physiology. Huazhong University of Science and Technology Press, Wuhan, 2000.

47. XU D.Q. Efficiency of photosynthesis. Shanghai Science and Technology Press. Shanghai, 2002.

48. PEI B., ZHANG G.C., ZHANG S.Y., WU Q., XU Z.Q., XU P. Effects of soil drought stress on photosynthetic characteristics and antioxidant enzyme activities in Hippophae rhamnoides Linn.seedings. Acta. Ecologica. Sinica. 33 (5), 1386, 2013.

49. XIA J.B., ZHANG S.Y., ZHAO X.M., LIU J.H., CHEN Y.P. Effects of different groundwater depths on the distribution characteristics of soil-Tamarix water contents and salinity under saline mineralization conditions. Catena. 142, 166, 2016.

50. ABEGUNRIN T.P., AWE G.O., IDOWU D.O., ADEJUMOBI M.A. Impact of wastewater irrigation on soil physico-chemical properties, growth and water use pattern of two indigenous vegetables in southwest Nigeria. Catena. 139 (3), 167, 2016.

51. LI X.L., ZHANG G.C., ZHOU Z.F., LIU X., CHEN X.J., ZHANG S.Y. Response to light of water utilization efficiency of walnut leaf in different soil moisture in loess hilly region. Science of Soil and Water Conservation. 3 (1), 43, 2005.

52. ZHANG G.C., LIU X., HE K.N. Grading of Robinia pseudoacacia and Platycladus orientalis woodland soil' s water availability and productivity in semi-arid region of Loess Plateau. Chinese Journal of Applied Ecology. 14 (6), 858, 2003.

53. CHEN X.J., ZHANG G.C., ZHOU Z.F., MA S.S., LI X.L., ZHANG S.Y. Diurnal variations and response to light of gas exchange parameters of clove (Syringa oblata Lindl.) leaf in loess hilly region. Science of Soil and Water Conservation. 2 (4), 102, 2004. 
